Artigos

Juliana Schumacker Lessa'

\title{
O conceito de experiência em Walter Benjamin: elementos para pensar a educação na infância
}

Resumo: O presente artigo é resultante de um estudo teórico sobre o conceito de experiência, discutido, analisado e refletido durante a realização de um seminário especial e nas reuniões de estudos mensais em grupo de pesquisa. As discussões se localizam no bojo da reflexão sobre a experiência da infância na modernidade, na interlocução com Walter Benjamin. Primeiramente, o texto se dedica a localizar como a noção de experiência se situa no interior da área da educação na infância, com particular ênfase sobre as propostas educativas. Num segundo momento, apresento como as ideias de infância e história são concebidas na perspectiva materialista-histórica de Benjamin para, posteriormente adentrar na reflexão sobre o conceito de experiência do autor, considerando a imbricação das noções de infância e história na compreensão deste conceito, especialmente, na reflexão sobre a experiência na infância contemporânea.

Palavras-chave: Infância; Experiência; Modernidade, Walter Benjamin.

\section{The concept of experience in Walter Benjamin: elements to think about education in childhood}

Abstract: This article is the result of a theoretical study on the concept of experience, discussed, analyzed and reflected while conducting special seminar and a monthly study reunion in a research group. The discussions are situated in the core center of reflection, about the experience of childhood in modernity in the interlocution with Walter Benjamin. Firstly the text is dedicated to find how the notion of experience is situated in the interior field of childhood education, with a particular emphasis on educative proposals. In a second instance, I present how childhood and history ideas are conceived in a materialistic and historic perspective of Benjamin, for a latter penetration into the reflection on the concept of experience of the author, considering the connection between childhood and the history notions in understanding this concept, especially, on the reflection about the experience in contemporary childhood.

Keywords: Childhood; Experience; Modernity; Walter Benjamin.

I Doutoranda no Programa de Pós-Gradução em Educação da Universidade Federal de Santa Catarina. Mestre em Educação pelo Programa de Pós-Gradução em Educação da Universidade Federal de Santa Catarina. E-mail: julianallessa@gmail.com 


\section{Introdução}

Este artigo ${ }^{1}$ resulta de um seminário especial oferecido pelo Programa de Pós-Graduação em Educação da Universidade Federal de Santa Catarina, chamado: Infância e História em Walter Benjamin e dos encontros mensais em grupo de estudo sobre o autor e suas ideias relacionadas à experiência e à infância.

Com exceção da sua teoria da história e do teatro barroco, Benjamin não elaborou uma teoria da infância e, assim como a infância, outros conceitos aparecem nos seus escritos de forma bastante fragmentada, pois que "não há, em Benjamin, um sistema filosófico: toda sua reflexão toma a forma do ensaio ou fragmento" (LÖWY, 2002, p. 199). É necessário pois, realizar uma espécie de navegação pelas suas obras, adentrar seus diferentes mares literários: narrativos, de um modo geral e manifestados sob diferentes formas: aforismos, teses, ensaios, resenhas, pequenos fragmentos, citações, montagem literária. Navegando por essas diferentes leituras, vai-se compreendendo, muitas vezes sendo envolto por uma leitura imagética, as elaborações conceituais de Benjamin, como a noção de experiência, de memória e de infância. Mas, por outro lado, só é possível compreender uma elaboração dessas noções em Benjamin se buscarmos entendê-las dentro de uma constelação da modernidade e, particularmente a crítica à modernidade.

A infância e suas materialidades, inscritas nos brinquedos, nos jogos despertam a atenção de Benjamin porque são tomados como aspectos da modernidade, seus materiais e o que tem esses aspectos são reveladores das contradições da vida moderna. A infância, assim como as crianças e os materiais culturais que fazem parte deste universo são interessantes a Benjamin porque são fenômenos marginais, que permitem conhecer a vida cotidiana e suas transformações,

Más que interesarse por los grandes momentos de la historia, los grandes hombres, las batallas, cede el lugar a la vida cotidiana de la ciudad, y lo que él llama la historia secreta de la ciudad, la anécdota. Le preocupan los anúncios, los escaparates, los carteles, toda clase de objetos efémeros, cartas, diarios personales, cualquier tipo de fenómenos marginales. Y esto es lo que le permite conocer la verdadera vida cotidiana del siglo XIX. Benjamin se consideraba a sí mismo una espécie de colecionista de retazos y residuos. (WECHSLER, $2015)^{2}$.

\footnotetext{
I Concebido como trabalho em processo, as reflexões que serão aqui apresentadas não tem como intenção apresentar a síntese do conceito de experiência em Benjamin, nem tampouco esgotar as possibilidades de argumentos que possam ajudar na compreensão das questões que se colocam.

2 Esta citação foi transcrita a partir do vídeo: "The passages of Walter Benjamin”. A documentary film. 55min. 20।4. Escrito, dirigido e produzido por WECHSLER, Judith.
} 
A partir do movimento dialético do pensamento, Benjamin constroi uma teoria da modernidade, ou melhor, um modo de compreender a modernidade. Na sua historiografia materialista, o movimento de pensar se dá na mesma medida do seu aquietamento, momento em que o pensamento se imobiliza ante uma constelação saturada de tensões:

Allí donde el pensar se para de pronto ante una constelación saturada de tensiones, provoca en la misma un shock mediante el que ella cristaliza como mónada. El historiador materialista accede a un objeto histórico sólo y exclusivamente cuando éste le sale al encuentro cómo mónada. (TIEDEMANN, 2005, p. 28)

A metáfora da mônada ajuda a entender como Benjamin concebia um modo historiográfico materialista-dialético, pois que o movimento do pensamento consiste em captar o tempo dentro de uma constelação que se irrompe e se cristaliza como uma mônada, formada por pequenas partículas históricas; aí está o objeto do materialismo-histórico: ele tem a imagem de uma mônada. "No es que lo pasado arroje luz sobre lo presente, o lo presente sobre lo passado, sino que imagen es aquello en donde lo que ha sido se une como un relâmpago ala hora en una constelación. En otras palabras: imagen es la dialéctica en reposo" (BENJAMIN, 2005, p. 465). Este modo não recusa o materialismo dialético de Marx, mas rechaça um marxismo vulgar e isso pode ser visto em "Sobre o conceito de história", onde o conceito de trabalho e de classes são questões que percorrem as teses. Acusando-os de um conceito corrompido do trabalho, Benjamin se coloca contra um marxismo vulgar:

\footnotetext{
Pressentindo o pior, Marx replicou que o homem que não possui outra propriedade que a sua força de trabalho está condenado a ser "o escravo de outros homens que se fizeram... proprietários." Apesar disso, a confusão continuou a propagar-se e pouco depois anunciava Josef Dietzgen: "O trabalho é o Salvador dos tempos modernos... No aperfeiçoamento... do trabalho reside a riqueza, que agora pode realizar o que não foi até o presente realizado por nenhum redentor." Esse conceito de trabalho, típico do marxismo vulgar, não examina a questão de como seus produtos podem beneficiar trabalhadores que não dispõem deles. Seu interesse dirige-se apenas aos progressos na dominação da natureza, e não aos retrocessos da sociedade. Já estão visíveis, nessa concepção os traços tecnocráticos que mais tarde vão aflorar no fascismo. (BENJAMIN, 2012, p. 247).
}

Como um aspecto mais global da obra benjaminiana, sua teoria da modernidade revela a crítica do seu tempo. E ainda que a duração do seminário tenha sido pouca para um estudo sobre a 
modernidade em Benjamin, a partir da troca com outros colegas que têm se dedicado aos estudos benjaminianos, vou aos poucos conseguindo montar o quebra-cabeças de peças teóricas fragmentadas e conseguindo perceber a constelação moderna de Benjamin. Ainda que cada pesquisador observe e estabeleça outras relações, que cada qual navegue com uma determinada bússola em direção a algum aspecto da sua obra, ou mesmo, refletindo sobre os mesmos conceitos, mas estabelecendo relações diferenciadas, conforme o objeto de estudo, destas trocas apareceram os textos sobre "Paris, capital do século XIX", sobre "Charles Baudelaire, um lírico no auge do capitalismo" e o compêndio de notas e reflexões que deram corpo à monumental obra sobre a modernidade, o “Livro das Passagens". Isso tudo, me levou a considerar esses diferentes olhares sob Walter Benjamin, despertando meu interesse em refletir a infância contemporânea no diálogo com a sua teoria crítica da modernidade.

Neste artigo, busco, inicialmente, localizar como a noção de experiência se situa no interior da área da educação na infância, com particular ênfase sobre as propostas educativas, motivo pelo qual incitou meu interesse por Benjamin, fundamentalmente, com relação às suas ideias de infância, história e experiência. Num segundo momento, apresento como as ideias de infância e história são concebidas na perspectiva materialista-histórica de Benjamin para, posteriormente adentrar na reflexão sobre o conceito de experiência do autor, considerando a imbricação das noções de infância e história na compreensão deste conceito, especialmente, na reflexão sobre a experiência na infância contemporânea. Como vimos, só é possível compreender a elaboração dessas noções em Benjamin se buscarmos entendê-las dentro de uma constelação da modernidade e, particularmente a crítica à modernidade.

conceito de experiência nas propostas educativas para a infância

O conceito de experiência é uma ideia que aparece com intensidade nas discussões da infância e aqui, me refiro mais especificamente à sua ligação nos discursos relacionados com os dispositivos educativos voltados à educação das crianças de 0 a 6 anos. No trecho que se segue encontramos a concepção de experiência na definição do que vem a ser o currículo para a infância nas políticas para a educação infantil: "Conjunto de práticas que buscam articular as experiências e os saberes das crianças com os conhecimentos que fazem parte do patrimônio cultural, artístico, ambiental, 
científico e tecnológico." (Diretrizes Curriculares Nacionais para a Educação Infantil - DCNEI, MEC, 2010, p. 12).

$\mathrm{Na}$ definição das propostas educativas para a infância, estas, devem tomar como eixos norteadores as interações e as brincadeiras, que busquem como horizonte garantir experiências que "promovam o conhecimento de si e do mundo por meio da ampliação de experiências sensoriais, expressivas, corporais (...);" que "possibilitem às crianças experiências de narrativas, (...)." (DCNEI, 2010. p. 25.). É enfim, por meio da "integração dessas experiências" (DCNEI, 2010, p. 27 grifos nossos) que devem ser elaboradas as propostas educativas.

$\mathrm{Na}$ área de estudos da educação na infância, a ideia de experiência tem, por um lado, uma contribuição da produção italiana, trazida por Ana Lúcia Goulart de Faria, sendo aprofundada e ampliada com os demais estudos por ela coordenado no Grupo de Estudos e Pesquisa em Diferenciação Sociocultural da Faculdade de Educação da Universidade Estadual de Campinas (GEPEDISC/UNICAMP). Nestes estudos, elabora-se uma ideia de experiência educativa inspirada nas propostas educativas italianas de campos de experiência. Ou seja, temos a influência de uma produção italiana trazida para o Brasil, cujas autoras de referência, Susanna Mantovani e Anna Bondioli, da Universidade de Milão produziram estudos em torno da ideia de campos de experiência, sobre a educação na infância. Na proposta italiana, segue-se uma perspectiva educacional para a pequena infância baseada numa Pedagogia das Relações. Essa perspectiva toma como pressuposto que a formação humana se dá na relação social, sendo a produção da subjetividade partilhada de significações coletivas. $\mathrm{Na}$ área, essas discussões deram forma a elaboração de um conjunto de especificidades pedagógicas e conceituais dando corpo ao que veio a ser chamado como uma Pedagogia da Educação Infantil. A construção reflexiva desse conjunto de especificidades "sedimentaram os princípios daquilo que, posteriormente, foi instituído como Pedagogia da Infância (FARIA, 1999; ROCHA,1999)3". Seria equivocado chamar a Pedagogia da Infância de uma teoria, pois que se trata da emergência de uma perspectiva pedagógica que se sedimenta da acumulação e contribuição de estudos da área da educação, que têm como enviesamento a crítica à reprodução de modelos educativos reducionistas e conservadores.

Podemos dizer, então, que a ideia de experiência tem, por um lado, uma contribuição da

3 Conforme conceitua Maria Carmen Silveira Barbosa no Dicionário de verbetes. Dicionário disponível na página eletrônica do Grupo de Estudos sobre Política Educacional e Trabalho Docente da Universidade Federal de Minas Gerais (http://www.gestrado.org/?pg=dicionario-verbetes\&id=312). Acessado em 4 de set. de 2015. 
produção italiana, porque apesar dessa produção consistir num documento de orientação nacional, contextualizado na Itália, quero dizer, as propostas italianas, que falam de experiência, ele também foi produzido, assim como no Brasil, com a contribuição das Universidades e vamos encontrar em vários textos da bibliografia italiana essa mesma ideia.

Outra abordagem do conceito de experiência que marca a área dos estudos da infância no país, pode ser lida a partir de Sônia Kramer e seu percurso de estudos no Grupo de Pesquisa sobre Infância, Formação e Cultura do Departamento de Educação da Pontifícia Universidade Católica do Rio de Janeiro (INFOC/PUC-RJ). Kramer e os estudos por ela coordenados tomam como referencial teórico ao falar da infância e sua educação, os estudos de Walter Benjamin "por sua teoria crítica da cultura e da modernidade, seu conceito de história e sua concepção de infância" (2009, p. 86) e os de Bakhtin e Vigotski, sobretudo apoiando-se nas suas teorias da linguagem. A partir dessas reflexões, Kramer agrega-se ao conjunto de estudos que sedimentam a Pedagogia da Infância, conceituando a criança "na sua condição de sujeito histórico que verte e subverte a ordem e a vida social” (KRAMER, 1996, p. 14):

Analiso, então, a importância de uma antropologia filosófica (nos termos que dela falava Walter Benjamin), perspectiva que, efetuando uma ruptura conceitual e paradigmática, toma a infância na sua dimensão não-infantilizada, desnaturalizando-a e destacando a centralidade da linguagem no interior de uma concepção que encara as crianças como produzidas na e produtoras de cultura. A crítica à pedagogização do conceito de infância e à pedagogização das tantas ações desenvolvidas com crianças é fio condutor da análise. (KRAMER, 1996, p. 14).

De modo muito esquemático apresentei aqui as duas influências que percorrem o conceito de experiência na área da educação e infância: a ideia italiana de campos de experiência, somada a afirmação de uma experiência educativa e também associada a aproximações, digamos, assim, conceituais com o uso de experiência pelos grupos que trabalham com Bakhtin, Vigostki e Benjamin. Como se pode ver, tantos as propostas educativas italianas recebem influência dos estudos produzidos na Universidade, como aqui no Brasil vemos essa mesma influência, o que quer dizer que falar das propostas nacionais para a infância implica estabelecer a autocrítica, a reflexividade necessária no interior da área de estudos. 
Infância e história em Benjamin

Ainda que tenhamos essas abordagens, as quais podemos compreender como basilares da noção de experiência no interior do debate da Pedagogia da Infância, o conceito de experiência vem sendo recorrentemente abordado na discussão relacionada às normativas curriculares para a educação infantil. Como uma pesquisadora da infância e que transita pelos espaços de formação de professores e nesse trânsito se defronta muitas vezes com estudos das propostas curriculares e políticas para educação infantil, desde o início das discussões dos textos benjaminianos uma pergunta me acompanhou: é possível pensar numa experiência infantil? E experiência esta, nos termos benjaminianos? Sendo assim, como o autor poderia me ajudar a pensar a experiência na infância? Na área da infância, quando falamos em proporcionar, integrar, ampliar, garantir, articular experiências que sejam significativas às crianças qual a raiz teórica da noção de experiência?

Antes de mais nada, é preciso deixar claro que Benjamin não desenvolve uma teoria sobre a infância, entretanto, sim, Benjamin escreve sobre a infância e sua educação e, ainda que escreva fragmentadamente e por meio de variadas expressões literárias, que nos remetem, como disse antes, a um pensamento imagético, podemos encontrar nos seus escritos uma concepção de infância. Benjamin escreve também para as crianças e fala sobre as crianças, e ao fazer isso, apesar de não dedicar-se à educação escolar, ele acaba mostrando como compreendia um modo de relação com aqueles recém-chegados ao processo civilizador ou, ao mundo moderno. Como disse Benjamin, é na infância, pois, que reside a capacidade de reconhecer o novo, de estranhar-se e introduzir esse novo estranho no espaço simbólico, e a essa tarefa de construção simbólica encarrega-se a infância:

\footnotetext{
Tarea de la infancia: introducir el nuevo mundo en el espacio simbólico. Pues el niño puede hacer aquello de lo que el adulto es completamente incapaz: reconocer lo nuevo. Para nosotros las locomotoras tienen ya un carácter simbólico, porque las encontramos en la infancia. Para nuestros niños lo tienen sin embargo los automóviles, en los que nosotros sólo hemos captado el lado nuevo, elegante, moderno, desenfadado. No hay antítesis más estéril e inútil que la que pensadores reaccionarios como Klages se esfuerzan en establecer entre el espacio simbólico de la naturaleza y el de la técnica. A toda configuración verdaderamente nueva de la naturaleza - y en el fondo la técnica es también una de ellasle corresponden nuevas "imágenes". Toda infancia descubre estas nuevas imágenes para incorporarlas al patrimonio de imágenes de la humanidad. (BENJAMIN, 2005, p. 395).
}

A tarefa de construir o mundo simbólico associada à infância talvez seja um dos aspectos 
mais centrais e de maior destaque para se relacionar a concepção benjaminiana de infância com a educação. A infância aparece em Benjamin pelos seus objetos materiais-históricos, como os brinquedos, os jogos, as fábulas, as coleções, os livros infantis. As crianças e a infância são os restos, dos quais Benjamin se interessa, a história dos vencidos e não a dos vencedores; aquela história que nos seus livros de escola aparecia em notas de rodapé e pelas quais ele se interessava:

Quando era jovem, aprendi História lendo o Neubauer, que ainda deve existir em muitas escolas, talvez hoje um pouco diferente do que era antes. Na época o que mais me chamava atenção era que as páginas eram divididas em caracteres grandes e pequenos. As páginas com caracteres grandes falavam de príncipes, guerras, tratados de paz, alianças, datas etc., coisas que tínhamos que decorar, e eu não achava muita graça. Em caracteres pequenos vinham as páginas com a, assim chamada, história das civilizações, contando sobre os costumes e tradições das pessoas em tempos antigos, suas crenças, sua arte, ciência, suas construções etc. Aquilo não era preciso decorar, bastava ler, o que era muito mais divertido. Por mim, as páginas impressas em caracteres pequenos poderiam ter sido em número muito maior. Não se ouvia falar muito sobre essas coisas durante a aula. $\bigcirc$ professor de alemão dizia: isto vocês vão ver na aula de História, e o professor de História: isto vocês vão ver na aula de alemão. No final acabávamos quase sempre sem ouvir nada." (BENJAMIN, 20I5, p. I8I).

Por outro lado, quando escreve "Infância berlinense por volta de 1900", Benjamin narra, na condição de um exilado em um outro país, Paris, sobre sua própria infância, vivida em Berlim, sendo contada por meio de aforismos aquela experiência que, pouco vemos como algo autobiográfico, pois que ao final das leituras não sabemos quase nada dos aspectos psicológicos do menino Benjamin, mas a experiência de uma infância na cidade, da sua história. Nesta parte da navegação pelos mares literários benjaminianos, se nada encontramos sobre o menino, podemos encontrar a história de uma infância burguesa, judia, berlinense que se passava na passagem do século 19 para o século 20, momento em que a infância encontra seu terreno fértil na história social. Por esses caminhos de leitura que torna possível compreender e afirmar que Benjamin fala de uma infância na modernidade. Em "História cultural do brinquedo" e "Brinquedos e jogos", vemos como o autor considera esses objetos como materiais histórico-culturais, o que permite ver um Benjamin materialista-histórico e aqui nesses dois textos é possível ter uma noção benjaminiana de criança, por exemplo, ao percebermos como ele toma os brinquedos como sinais entre a criança e o povo: "Pois se a criança não é nenhum Robinson Crusoé, assim também as crianças não constituem nenhuma comunidade isolada, mas antes fazem parte do povo e da classe a que pertencem” (BENJAMIN, 2002, p. 94). 
A noção de infância aparece na crítica dialética à modernidade que o autor constrói ao analisar os brinquedos e os jogos. Neste trecho, ainda que não fale da formação da criança na escola, é possível ver em Benjamin uma concepção de infância, na qual a seriedade e a inteligência da criança aparecem como elementos a serem considerados nos seus processos de formação humana, uma não-infantilização da infância, como colocado anteriormente por Kramer:

Para a criança que brinca, a sua boneca é ora grande, ora pequena, e certamente pequena com mais frequência, pois se trata de um ser subordinado. Isso se deve muito mais ao fato de que até o século XIX adentro o bebê era inteiramente desconhecido enquanto ser inteligente e, por outro lado, o adulto constituía para o educador o ideal a cuja semelhança ele pretendia formar a criança. Em todo caso, ainda nesse racionalismo hoje em dia tão zombado, que via na criança o pequeno adulto, fazia-se pelo menos justiça à seriedade enquanto esfera adequada à criança" (BENJAMIN, 2002, p. 98).

Em Brinquedos e jogos é possível perceber como a infância encontra um espaço fecundo na modernidade, ao vermos Benjamin falando sobre a tendência do seu tempo para as pesquisas em torno dos objetos culturais para e da infância. Neste mesmo trecho, vemos a crítica à imagem da criança apresentada pela psicologia individual e aos brinquedos que na verdade expressavam mais as necessidades pueris próprias dos adultos, como as bonecas de traços realistas. O rompimento com a influência deste tipo de psicologia e de esteticismo abriu caminhos para a arte popular e para uma concepção infantil do mundo compreendidas como configurações coletivas:

\begin{abstract}
A tendência para tais pesquisas é uma característica da época. $\bigcirc$ Museu Alemão em Munique, o Museu de Brinquedos em Moscou, a seção de brinquedos do Musée des Arts Décoratifs em Paris - criações do passado mais recente ou do presente - demonstram que por toda parte, e certamente por boas razões, o interesse por brinquedos autênticos está despertando. Chegou ao fim a era das bonecas com traços realistas, época em que os adultos pretextavam supostas necessidades infantis para satisfazer as próprias necessidades pueris. $\bigcirc$ individualismo esquemático do artesanato e a imagem da criança apresentada pela psicologia individual - os quais, no fundo, entendiam-se tão bem - foram rompidos por dentro. Ao mesmo tempo, ousou-se dar os primeiros passos para sair do círculo de influência da psicologia e do esteticismo. A arte popular e a concepção infantil do mundo desejavam ser compreendidas como configurações coletivas (BENJAMIN, 2002, p. 96).
\end{abstract}

Estes dois últimos textos, "História cultural do brinquedo" e "Brinquedos e jogos", ao trazerem os objetos culturais próprios da infância, ao falar da criança, ao falar de uma história que não era contada têm estreita relação com as teses "Sobre o conceito de história", onde podemos ver 
a construção de Benjamin do conceito de história a partir da contraposição com uma história universal, com o que o autor vai chamar de historicismo, uma história dos vencedores:

\begin{abstract}
Impossível caracterizar melhor o método com o qual rompeu o materialismo histórico. Esse método é o da empatia (Einfuhlung). Sua origem é a inércia do coração, a acedia, que desanima de apropriar-se da autêntica imagem histórica, em seu relampejar fugaz. Para os teólogos medievais, a acedia era o primeiro fundamento da tristeza. (...). A natureza dessa tristeza se tornará mais clara se nos perguntarmos com quem o investigador historicista estabelece propriamente uma relação de empatia. A resposta é inequívoca: com o vencedor. Ora, os que num dado momento dominam são os herdeiros de todos os que venceram antes. A empatia com o vencedor beneficia sempre, portanto, esses dominadores. Isso já diz o suficiente para o materialista histórico. Todos os que até agora venceram participam do cortejo triunfal, que os dominadores de hoje conduzem por sobre os corpos dos que hoje estão prostrados no chão. Os despojos são carregados no cortejo triunfal, como de praxe. Eles são chamados de bens culturais. O materialista histórico os observa com distanciamento. Pois todos os bens culturais que ele vê têm uma origem sobre a qual ele não pode refletir sem horror (BENJAMIN, 20I2, p. 244-245).
\end{abstract}

conceito de experiência nos escritos benjaminianos

O homem de hoje não cultiva mais aquilo que não pode ser abreviado.

(Valéry, 1960, p. 1244)

Mas a noção de experiência aparece mesmo em "Experiência e pobreza" e "O narrador". Falar de experiência nos escritos de Benjamin implica falar em duas formas de como ele escreve sobre esta noção, uma delas, por meio de breves reflexões por ele desenvolvida nestes dois ensaios, que conceituam a experiência na modernidade a partir da negação da sua possibilidade com o desenvolvimento acelerado da técnica.Por outro lado, Benjamin, como vimos antes, também escreve sobre a experiência a partir da própria infância, da narrativa de uma infância urbana, berlinense. Assim, em Benjamin, falar de experiência, antes de mais nada, significa falar de uma experiência com o mundo moderno e suas transformações.

A experiência benjaminiana relaciona-se com a memória, com aquilo que é passado de geração em geração, aquilo que tem o peso da tradição e que, por se situar no âmbito da transmissão geracional, nos permite relacionar seu conceito com a educação. Para Benjamin, a experiência é a transmissão de histórias pela narração:

ela sempre fora comunicada pelos mais velhos aos mais jovens. De forma concisa, com a autoridade da velhice, em provérbios; de forma prolixa, com a sua loquacidade, em his- 
tórias; às vezes como narrativas de países longínquos, diante da lareira, contadas a filhos e netos" (BENJAMIN, 2012, p. 123).

A experiência é, portanto, aquilo que pode ser transmitido de geração em geração, e esta ideia nos leva a relacionar o ato de transmitir como um ato educativo, formativo, ou seja, nesta compreensão, a experiência está no cerne da formação humana. Entretanto, com o "monstruoso desenvolvimento da técnica" atingimos "uma forma completamente nova de miséria" (BENJAMIN, 2012, p. 124), a pobreza de experiência. A uma modernidade técnica, transforma-se "os homens antigos em criaturas inteiramente novas (...). De resto, essas criaturas também falam uma língua inteiramente nova" (BENJAMIN, 2012, p. 126). Essa incapacidade de narrar, de transmitir experiência, em Benjamin aparece como um sintoma da modernidade que quer apagar os restos, o residual, aquilo do passado que sobra no presente, pois que o pensamento moderno, científico, não permite espaço para a dúvida, é necessário sair à caça às bruxas e positivar todo e qualquer vestígio de mistério, de tradição. Essa caça às bruxas seria, para Benjamin, a morte da experiência, que significa a morte da história, e de uma história residual, dos vencidos, dos fenômenos marginais da vida cotidiana. Seria a eterna tentativa de apagamento de tudo que é história, que é tradição, seria esse apagamento sutil e conformado porque em nome de tudo que é científico, de tudo que pode ser experimentado e não experiência do sujeito: a experiência foi expelida do sujeito pelo pensamento moderno.

Aqui, neste momento da reflexão penso nos livros infantis, nas fábulas, que ainda sobrevivem na infância e que nos remetem à tradição, à narração, à experiência. Fábulas de bruxas, de personagens típicos de uma dada cultura, figuras e fatos misteriosos que rondam a história, aparecem como possibilidades de experiência e fornecem pistas que garantam essas possibilidades na infância contemporânea.

O primeiro narrador verdadeiro é e continua sendo o narrador de conto de fadas. Esse conto sabia dar um bom conselho quando ele era difíicil de obter, e era o primeiro a ajudar em caso de emergência. Essa emergência era a emergência provocada pelo mito. O conto de fadas revela-nos as primeiras medidas tomadas pela humanidade para libertar-se do pesadelo que o mito havia infundido em nossos corações. Ele nos mostra, (...) no personagem do animal que socorre uma criança, (...) que a natureza prefere associar-se ao homem do que ao mito (...). O feitiço libertador do conto de fadas não põe em cena a natureza como uma entidade mítica, mas indica a sua cumplicidade com o homem liberado. $\bigcirc$ adulto percebe essa cumplicidade apenas ocasionalmente, isto é, quando está feliz; para a criança, ela aparece pela primeira vez no conto de fadas e provoca nela uma sensação de felicidade (BENJAMIN, 20I2, p. 232-233). 
As fábulas nadam contra a maré de estímulos incessantes, efêmeros e fugazes as quais somos o tempo todo rodeados na vida cotidiana. As massas, a massificação das informações, das imagens, a produção em série da indústria cultural, tem o poder de alcançar a formatação das subjetividades, de produzirem a subjetividade, de aniquilarem a experiência. A fábula não se externaliza do sujeito, a fábula media uma relação entre pensamento e linguagem, assim como a arte: ao ouvir contos, a criança-ouvinte perlabora o que ouve na sua imaginação, cria imagens, transforma em ação mimética, mimetisa e cria memória... Assim entendo como funciona o conceito de experiência em Benjamin, assim o relaciono com a possibilidade de experiência infantil.

\begin{abstract}
Não são as coisas que saltam das páginas em direção à criança que as vai imaginando - a própria criança penetra nas coisas durante o contemplar, como a nuvem que se impregna do esplendor colorido desse mundo pictórico. Diante de seu livro ilustrado, a criança coloca em prática a arte dos taoístas consumados: vence a parede ilusória da superfície e, esgueirando-se por entre tecidos e bastidores coloridos, adentra um palco onde vive o conto maravilhoso. (...). Nesse mundo permeável, adornado de cores, em que a cada passo as coisas mudam de lugar, a criança é recebida como participante. Fantasiada com todas as cores que capta lendo e contemplando, a criança se vê em meio a uma mascarada e participa dela. Lendo - pois se encontraram as palavras apropriadas a esse baile de máscaras, palavras que revolteiam confusamente no meio da brincadeira como sonoros flocos de neve. (...). Ao elaborar histórias, crianças são cenógrafas que não se deixam censurar pelo "sentido" (BENJAMIN, 2002, p. 69-70).
\end{abstract}

Nas “Narrativas Radiofônicas”, é possível ver a maneira como Benjamin pensava a ideia de experiência, particularmente a experiência infantil, mediada na figura do narrador e do ouvinte, pela narrativa. As narrativas de Benjamin para as crianças dão forma aquela experiência do viajante e do velho sábio, ou seja, uma experiência que está no espaço e está no tempo. Um espaço-tempo tecido de relações materiais e culturais, como a do marinheiro-comerciante que viaja e estabelece muitas e diversificadas relações, como a daquele que já viveu muito, que é possuidor de uma sabedoria de vida.

A experiência que passa de boca em boca é a fonte a que recorreram todos os narradores. $E$, entre as narrativas escritas, as melhores são as que menos se distinguem das histórias orais contadas pelos inúmeros narradores anônimos. Entre estes últimos existem dois grupos que se interpenetram de múltiplas maneiras. A figura do narrador só se torna plenamente tangível se tivermos presentes ambos esses grupos. "Quem viaja tem muito a contar", diz o povo, e com isso imagina o narrador como alguém que vem de longe. Mas também escutamos com prazer o homem que ganhou honestamente sua vida sem sair do seu país e que conhece suas histórias e tradições. Se quisermos concretizar esses dois grupos através dos seus representantes arcaicos, podemos dizer que um é exemplificado 
pelo camponês sedentário, e o outro pelo marinheiro comerciante. De fato, ambos estilos de vida produziram de certo modo suas respectivas linhagens de narradores. Cada uma delas conservou, no decorrer dos séculos, suas características próprias. Essas duas linhagens constituem, como já foi dito, apenas tipos fundamentais. A extensão real do reino narrativo, em todo o seu alcance histórico, só pode ser compreendida se levarmos em conta a íntima interpenetração desses dois tipos arcaicos (BENJAMIN, 2012, p. 214-215).

Grandes catástrofes naturais, grandes catástrofes ferroviárias, crianças, bandoleiros, presidiários para falar dos silenciados, os comerciantes para falar da arte da comunicabilidade narrativa, bruxas e ciganos para falar do mito, da passagem de um pensamento mágico para um pensamento científico, para falar de uma modernidade técnica, é isso que podemos encontrar Nas "Narrativas Radiofônicas", e Benjamin fala o tempo todo dialeticamente, seu pensamento se movimenta. Assim, penso que Benjamin ajuda a pensar a experiência na infância contemporânea, percebendo a infância como uma mônada formada por pequenas partículas históricas, dentre elas a história de uma infância que encontra seu lugar no mundo moderno e que se configura a partir da dialética da modernidade.

Referências bibliográficas

BENJAMIN, W. Charles Baudelaire: um lírico no auge do capitalismo (Obras Escolhidas v. III). São Paulo: Editora Brasiliense, 1989. 34, 2002.

Reflexóes sobre a criança, o brinquedo e a educaçáo. São Paulo: Duas Cidades; Ed.

Libro de los pasajes. Madrid: Ediciones Akal, 2005.

Magia e técnica, arte e política: ensaio sobre literatura e história da cultura (Obras Escolhidas v. I). São Paulo: Brasiliense, 2012.

. Infância berlinense: 1900. In: BENJAMIN, W. Rua de mão única. Infância berlinense: 1900. Belo Horizonte: Autêntica Editora, 2013, pp. 67-116.

A hora das crianças: narrativas radiofônicas. Rio de Janeiro: NAU Editora, 2015.

BRASIL. Ministério da Educação. Secretaria de Educação Básica. Diretrizes curriculares nacionais para a educaçáo infantil. Brasília: MEC, SEB, 2010.

FARIA, Ana Lúcia Goulart de. Da escola materna à escola da infância: a pré-escola na Itália hoje. Cadernos CEDES, v. 15, p. 63-67, 1995.

KRAMER, Sônia; GUIMARÃES, Daniela. Nos espaços e objetos das creches, concepçóes de educação e práticas com crianças de 0 a 3 anos. In: KRAMER, Sônia (Org.). Retratos de um desafio: crianças e adultos na educaçáo infantil. São Paulo: Ática, 2009, pp. 82-94.

KRAMER, Sônia. Pesquisando a infância e educação: um encontro com Walter Benjamin. In: KRAMER, Sônia; LEITE, Maria Isabel. (Orgs.). Infância: fios e desafios da pesquisa. Campinas /SP: Papirus, 1996, pp. 13-38.

LÖWY, Michael. A filosofia da história de Walter Benjamin. Estudos Avançados, v. 16 (45), 
2002, pp. 199-206.

TIEDEMANN, Rolf. Introducción del editor. In: BENJAMIN, W. Libro de los pasajes. Madrid: Ediciones Akal, 2005, pp. 9-33.

VÍDEO - “The passages of Walter Benjamin”. A documentary film. 55min. 2014. WECHSLER, Judith (escritora, diretora e produtora); O'CONOR, Erika Volchan (editora). Publicado na plataforma online de vídeos YouTube em 24 de fev. de 2014. Disponível em: https://www.youtube.com/watch? $v=$ rsbzzMRdIBg. Acessado em 3 de set. de 2015. 